J. Lake Sci. (湖泊科学), 2021, 33(5): 1574-1583

DOI 10. 18307/2021. 0515

(C) 2021 by Journal of Lake Sciences

\title{
城镇化下流域不透水面扩张对洪峰的影响——南京秦淮河为例”
}

\author{
孙延伟,许有鹏”, 高 斌, 王 强, 李升峰 \\ (南京大学地理与海洋科学学院,南京 210023)
}

\begin{abstract}
摘 要: 长江下游秦淮河流域近年来由于城市化崛起导致不透水面迅速扩张, 改变了流域水文过程, 导致暴雨洪水灾害 风险增大. 本文以南京秦淮河流域为例, 基于 1988-2015 年间下垫面和水文气象资料建立了流域水文模型, 通过不透水 面扩张情景分析, 探讨了 1988-2015 年间不透水面空间扩张及对流域洪水过程的影响. 研究结果表明: (1) 秦淮河全流 域 1988-2015 年不透水率从 3.92\% 增长到 19.11\%, 且不同区域扩张速度有所差异; (2) 2006-2015 年不透水面情景下的 洪峰流量平均涨幅大于城市化初期; 受流域上下游位置和下垫面地形条件的影响, 流域溧水河和句容河两河源处的不透 水面变化对洪峰的影响较流域下游出口处更显著; (3) 秦淮河流域及不同位置的不透水面扩张情景下,小洪水的洪峰响 应均大于大洪水,且不透水面扩张发生在下游主干河流域时的大、小洪水洪峰涨幅差距略大于河源流域.
\end{abstract}

关键词: 洪峰流量;不透水面;空间分布;城市化;秦淮河流域

\section{Influence of impervious surface expansion on flood peak under urbanization-A case study of Qinhuai River in Nanjing *}

Sun Yanwei, Xu Youpeng ${ }^{* *}$, Gao Bin, Wang Qiang \& Li Shengfeng

(School of Geography and Ocean Sciences, Nanjing University, Nanjing 210023, P.R.China)

\begin{abstract}
In recent years, the impervious surface of Qinhuai River Basin in the lower reaches of the Yangtze River has expanded rapidly due to the rise of urbanization, which has changed the hydrological process of the basin and increased the risk of rainstorm and flood disasters. This paper takes the Qinhuai River Basin of Nanjing as an example, establishes a watershed hydrological model based on underlying surface and hydrometeorological data from 1988 to 2015 . Through the analysis of impervious surface expansion scenarios, the spatial expansion of impervious surface from 1988 to 2015 and their impact on the flooding process of the basin is discussed. The research results show that: (1) The impervious rate of Qinhuai River Basin increased from 3.92\% to 19.11\% from 1988 to 2015, and the expansion speed is different in different regions; (2) The average increase of flood peak discharge under impervious surface scenarios from 2006 to 2015 was greater than that at the beginning of urbanization; Affected by the location of the upper and lower reaches of the basin and the terrain conditions of the underlying surface, the impact of impervious surface changes at the headwaters of the Lishui River and Jurong River on the flood peak discharge is more significant than that at the outlet of the downstream; (3) Under impervious surface expansion scenarios of Qinhuai River Basin and different locations, the flood peak discharge response of small floods is greater than that of large floods, and when the impervious surface expansion occurs in the main downstream basin, the difference between the peak increase of large and small floods is more significant than that at the headwaters.
\end{abstract}

Keywords: Flood peak discharge; impervious surface; spatial distribution; urbanization; Qinhuai River Basin

城市化是社会经济发展的必然趋势,城市地区社会经济和人口高度集中. 快速城市化导致以沥青、水泥 路面和墙体等为代表的不透水面大规模扩张, 取代了透水性较好的林地和草地等自然下垫面,改变了区域 水文循环过程. 随着城市化地区暴雨洪水事件频发,洪涝灾害威胁增大,探讨城市化暴雨洪水过程影响成为

* 2020-09-28 收稿;2021-01-11 收修改稿.

国家重点研发计划项目(2018YFC1508201)、国家自然科学基金项目 (41771032,41771029,41371044) 和江苏省水 利科技项目 (2019028) 联合资助.

** 通信作者; E-mail:xuyp305@163.com. 
了水文、地理和大气等学科关注的热点及前沿科学问题之一 ${ }^{[1-3]}$.

针对城市化背景下的暴雨洪水频发等问题, 国内外学者主要基于观测实验 ${ }^{[4-6]}$ 和数值模拟 ${ }^{[7-8]}$ 等方面开 展研究. 从流域整体上的洪水过程响应来看, 相关研究结果均表明城市化过程中不透水面的不断扩张影响 了雨水截留、下渗、蒸发等产汇流过程, 从而导致了洪峰流量增大、洪量增多和汇流速度加快 ${ }^{[9-14]}$. 其中针对 城市化下不透水面率的洪水效应, 国内外学者认为随着不透水率的增加, 洪峰流量和洪量变化显著并呈线 性增长关系 ${ }^{[15-17]}$. 然而, 由于气象和下垫面条件分布的不均匀性, 洪水响应在流域空间上也存在一定差异 性 ${ }^{[18-19]}$. 随着水文观测资料的丰富以及分布式水文模型的发展, 相关学者进一步探讨了城市化空间格局对 洪水的影响. 相关研究表明流域内部相比流域出口的城市化带来的洪水差异更为显著 ${ }^{[20]}$, 其中流域上游城 市化的影响尤为突出 ${ }^{[21-22]}$. 深人系统研究不透水面对洪水的影响对于城镇化的合理发展、水资源管理和防 洪减灾都具有重要的意义,但由于城市化地区洪水响应的复杂性,城市化的空间扩张格局对洪水的影响机 制尚不明确 ${ }^{[6]}$,其中不透水面积与洪水特性关系的深层次规律还有待进一步揭示.

因此,本文以长三角地区典型城市化流域一一南京 秦淮河流域为例,基于流域水文模拟模型, 考虑流域不 透水面扩张的不同情景, 重点研究城市化空间格局的洪 水效应差异, 分析不透水面扩张发生在流域不同位置时 对流域洪峰增长的影响, 揭示秦淮河流域不透水面积与 洪水特征之间的关系, 研究结果将为秦淮河流域及类似 快速城市化地区防洪减灾和可持续发展提供理论依据.

\section{1 研究区概况}

秦淮河流域地处长江下游三角洲地区, 整个流域呈 扇形, 流域面积约为 $2631 \mathrm{~km}^{2}$. 流域位于亚热带半湿润季 风气候区, 多年平均气温为 $15.4^{\circ} \mathrm{C}$, 降水丰沛 (图 1), 年 降水量在 1988-2015 年间总体呈增加趋势, 年均降水量 $1131.84 \mathrm{~mm}$. 流域雨季时间较长, 有 3 个明显多雨期, 分 别为 4 月 -5 月上旬, 6 月下旬 -7 月上旬的梅雨期及 $8-$ 9 月 ${ }^{[23]}$. 秦淮河有溧水河和句容河两源, 在南京市江宁区 汇合为秦淮河干流, 干流在江宁区东山镇发生分流, 流域 为双出口流域, 东侧支流由武定门出水口汇人长江, 西侧 支流为人工开丵河流秦淮新河, 在秦淮新河闸出水口人 长江. 流域内大部分河道为山丘河道, 上游支流众多且多 分布在山区, 暴雨后流量涨幅较大, 汇流速度快, 中下游 地区由于地势平坦, 内涝难排, 防洪压力大. 流域洪涝灾 害主要受气象因素、水系特征、过境洪水、地形条件等自 然因素和包括下垫面变化、河道整治和闸原圩垸等在内 的人类活动的共同影响 ${ }^{[24-26]}$, 本文的目标是探讨在秦淮 河流域城市化快速崛起的背景下, 不透水面扩张对洪水 洪峰流量带来的影响.

\section{2 数据与研究方法}

\section{1 数据资料}

本文选取 1996-2015 年间发生的 10 场涵盖不同 量级大小的暴雨洪水事件,各场次洪水过程的持续时间
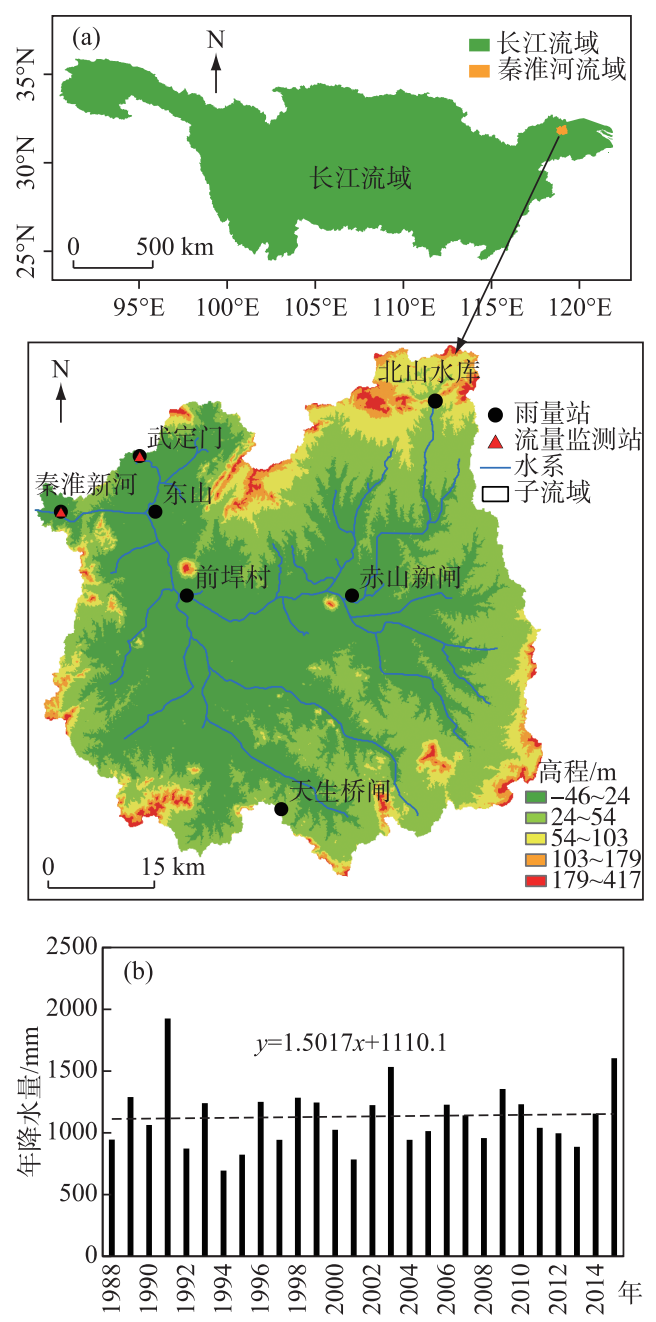

图 1 研究区位置 $(a)$ 和降水量 $(b)$

Fig.1 Location of study area (a) and the amount of precipitation ( $b$ ) 为 $2 \sim 12$ 天不等. 降雨站点为前垾村、天生桥闸等 7 个 
雨量站, 数据间隔为小时尺度; 径流量数据为秦淮新河闸和武定门闸两个站点的径流量作为整个流域的径 流实测资料. 数字高程模型 (DEM) 来源为地理空间数据云平台, 并根据流域 DEM 数据与水系资料将秦淮河 流域划分成 19 个子流域. 土地利用数据来源于解译流域 1988-2015 年间的 8 幅 Landsat 系列的 TM、ETM+和 OLI 遥感影像, 结合遥感影像地物光谱并考虑流域内土地利用实际现状利用决策树分类法进行不透水面的 提取 ${ }^{[27]}$, 不透水面是指由各种不透水建筑材料所覆盖的表面, 如由瓦片、沥青、水泥混凝土等材料构成的屋 顶、道路和广场.

\section{2 研究方法}

2.2.1 秦淮河流域水文模型建立 基于 HEC-HMS (hydrologic engineering center's hydrologic modeling system) 水文模拟模型, 根据秦淮河流域实际情况构建了秦淮河流域水文模型, 主要由流域模块、气象模块、时间序 列数据模块和控制运行模块组成,将降雨径流的形成过程分为降雨损失、直接径流、基流、河道汇流 4 个部 分. 模型考虑了秦淮新河闸和武定门闸流域双出口的处理, 同时对流域内较大的圩垸考虑其运行规则综合 到模型中 ${ }^{[28]}$, 以反映流域的实际情况. 由于初损后损法计算模型产流适用于短历时强降雨、洪峰为单峰的 情况, Snyder 单位线法、马斯京根法、退水曲线法参数较少, 易于建立和使用, 且在洪涝模拟方面已经得到了 很好的应用 ${ }^{[29-30]}$, 因此本研究中根据流域情况产流计算采用初损后损法, 河道汇流演算选用马斯京根法, 直 接径流采用 Snyder 单位线法,基流采用退水曲线法.

2.2.2 模型率定和检验 流域水文模型需要率定的参数包括流域滞时、峰值系数、衰减系数、峰值比 $R$ 、蓄量 常数 $K$ 和流量比重 $X$ 等 (表 1,2$)$. 模型依据秦淮河流域的实测数据资料, 在已有研究基础上 ${ }^{[8,19]}$, 采用人工

表 1 各子流域率定参数

Tab. 1 Calibration parameters of each subbasin

\begin{tabular}{cccccccccc}
\hline 编号 & 流域滞时/ $\mathrm{h}$ & 峰值系数 & 衰减系数 & 峰值比 & 编号 & 流域滞时/ $\mathrm{h}$ & 峰值系数 & 衰减系数 & 峰值比 \\
\hline W1 & 4.2 & 0.23 & 0.88 & 0.18 & $\mathrm{~W} 11$ & 4.6 & 0.23 & 0.89 & 0.05 \\
W2 & 3.5 & 0.23 & 0.91 & 0.10 & $\mathrm{~W} 12$ & 3.7 & 0.23 & 0.90 & 0.15 \\
W3 & 3.4 & 0.23 & 0.93 & 0.10 & $\mathrm{~W} 13$ & 4.9 & 0.26 & 0.89 & 0.10 \\
W4 & 4.5 & 0.25 & 0.85 & 0.15 & $\mathrm{~W} 14$ & 4.6 & 0.24 & 0.90 & 0.01 \\
W5 & 4.3 & 0.23 & 0.92 & 0.01 & $\mathrm{~W} 15$ & 4.2 & 0.23 & 0.95 & 0.20 \\
W6 & 3.6 & 0.23 & 0.91 & 0.10 & $\mathrm{~W} 16$ & 3.5 & 0.24 & 0.91 & 0.10 \\
W7 & 3.3 & 0.26 & 0.90 & 0.05 & $\mathrm{~W} 17$ & 3.1 & 0.24 & 0.91 & 0.01 \\
W8 & 3.6 & 0.24 & 0.89 & 0.15 & $\mathrm{~W} 18$ & 3.5 & 0.25 & 0.92 & 0.20 \\
W9 & 4.0 & 0.26 & 0.87 & 0.09 & $\mathrm{~W} 19$ & 3.1 & 0.24 & 0.90 & 0.20 \\
W10 & 4.7 & 0.25 & 0.90 & 0.20 & & & & & \\
\hline
\end{tabular}

表 2 河道汇流率定参数

Tab.2 Calibration parameters of river confluence

\begin{tabular}{cccccc}
\hline 编号 & $K / \mathrm{h}$ & 流量比重 $X$ & 编号 & $K / \mathrm{h}$ & 流量比重 $X$ \\
\hline R1 & 2.0 & 0.10 & $\mathrm{R} 13$ & 2.1 & 0.11 \\
R2 & 2.2 & 0.13 & $\mathrm{R} 14$ & 2.1 & 0.11 \\
R3 & 2.0 & 0.10 & $\mathrm{R} 15$ & 1.5 & 0.07 \\
R4 & 2.3 & 0.13 & $\mathrm{R} 16$ & 2.2 & 0.10 \\
R5 & 2.0 & 0.10 & $\mathrm{R} 17$ & 2.0 & 0.10 \\
R6 & 2.4 & 0.14 & $\mathrm{R} 18$ & 2.2 & 0.13 \\
R7 & 1.1 & R19 & 2.6 & 0.08 \\
R8 & 1.7 & 0.06 & $\mathrm{R} 20$ & 2.0 & 0.10 \\
R9 & 2.1 & 0.10 & 2.4 & 0.14 \\
R10 & 1.7 & 0.10 & $\mathrm{R} 22$ & 2.0 & 0.10 \\
R11 & 2.0 & 0.10 & $\mathrm{R} 23$ & 2.0 & 0.10 \\
R12 & 1.4 & 0.07 & $\mathrm{R} 24$ & & \\
\hline
\end{tabular}


试错法对参数进行优化率定和检验. 首先将 10 场洪水随机分成两组, 以其中 4 场洪水数据来率定模型参数, 然 后利用其余 6 场洪水实测数据检验参数, 得到模型率定与检验结果 (表 3 ), 部分场次洪水的模拟过程与实测过 程比较见图 2. 可以发现, 率定期内的 4 场洪水模拟结果的纳什系数平均为 0.82 , 相关系数 $\left(R^{2}\right)$ 平均达到 0.86 ; 检验期 6 场洪水模拟结果的纳什系数平均为 0.83 ,相关系数平均为 0.87 ,总体模型验证效果较好.

表 3 洪水事件的模型率定及检验结果

Tab.3 Model calibration and test results of flood events

\begin{tabular}{|c|c|c|c|c|}
\hline & 洪水场次 & 土地利用时间 & 纳什系数 & $R^{2}$ \\
\hline \multirow[t]{4}{*}{ 模型率定 } & 199607 & 1988 年 & 0.77 & 0.82 \\
\hline & 201007 & 2011 年 & 0.88 & 0.92 \\
\hline & 201207 & 2011 年 & 0.81 & 0.84 \\
\hline & 201407 & 2013 年 & 0.82 & 0.88 \\
\hline \multirow[t]{6}{*}{ 模型检验 } & 200808 & 2006 年 & 0.90 & 0.95 \\
\hline & 200907 & 2009 年 & 0.74 & 0.81 \\
\hline & 201106 & 2011 年 & 0.90 & 0.91 \\
\hline & 201107 & 2011 年 & 0.73 & 0.81 \\
\hline & 201208 & 2011 年 & 0.82 & 0.92 \\
\hline & 201307 & 2013 年 & 0.88 & 0.92 \\
\hline
\end{tabular}
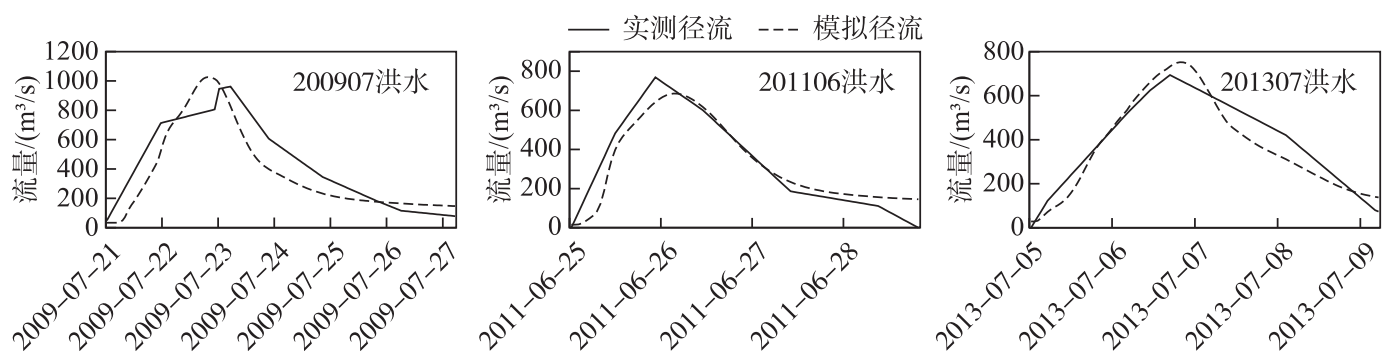

图 2 部分场次洪水模拟过程与实测过程的比较

Fig.2 Comparison between simulated and measured flood processes of some stations

\section{3 结果与讨论}

\section{1 流域不透水面扩张的时空变化分析}

近 30 年来,秦淮河全流域不透水面显著扩张, 不透水率从 $3.92 \%$ 增长到 $19.11 \%$ (表 4). 全流域在20062015 年的不透水面年均增长率为 $6.19 \%$,大于 2006 年之前; 研究区内各行政单元的城市化进程也有所差 异, 图 3 为研究时段内各行政单元不透水面扩张的空间分布情况:南京城区和江宁区在 1988-2006 年间不

表 4 秦淮河流域历年不透水率及不透水面年均增长率统计

Tab.4 Statistics of impervious rate and average annual growth rate of impervious surface in Qinhuai River Basin

\begin{tabular}{|c|c|c|c|c|c|c|c|c|c|c|}
\hline \multirow{2}{*}{ 区域 } & \multicolumn{8}{|c|}{ 不透水率/\% } & \multicolumn{2}{|c|}{ 年均增长率/\% } \\
\hline & 1988 年 & 1994 年 & 2001 年 & 2006 年 & 2009 年 & 2011 年 & 2013 年 & 2015 年 & $1988-2006$ 年 & $2006-2015$ 年 \\
\hline 南京城区+江宁区 & 4.45 & 6.43 & 11.98 & 17.90 & 21.30 & 25.39 & 26.06 & 28.85 & 8.04 & 5.44 \\
\hline 溧水区 & 2.91 & 3.14 & 5.98 & 6.52 & 8.62 & 12.10 & 11.20 & 14.88 & 4.58 & 9.60 \\
\hline 句容市 & 3.75 & 2.49 & 5.61 & 4.99 & 6.27 & 7.16 & 9.94 & 9.08 & 1.60 & 6.87 \\
\hline 全流域 & 3.92 & 4.40 & 8.58 & 11.13 & 13.52 & 16.34 & 17.49 & 19.11 & 5.97 & 6.19 \\
\hline
\end{tabular}


透水面的扩张明显, 年均增长率为 $8.04 \%, 2006$ 年之后不透水面虽然持续扩张, 但年均增长率略有下降, 为 $5.44 \%$; 而溧水区和句容市在 2006 年之前不透水面的扩张则较慢, 从 2006 年开始不透水面扩张速度显著加 快, 且年均增长率超过了南京城区和江宁区. 南京城区和江宁区作为城市化进程开始较早的区域, 随着未来 不透水面渐趋饱和, 其扩张速度可能会继续放缓, 而溧水区和句容市还处于城镇化较早时期, 未来不透水面 扩张潜力较大.
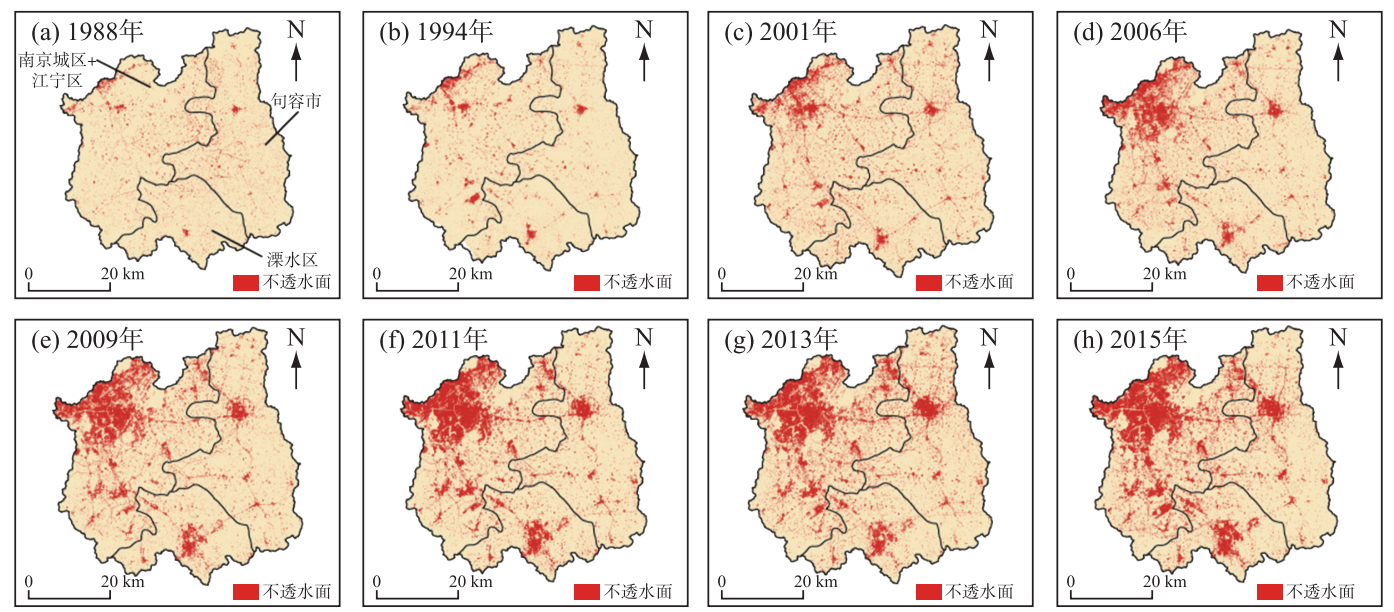

图 3 1988-2015 年流域不透水面空间分布

Fig.3 Spatial distribution of impervious surface in the basin from 1988 to 2015

\section{2 不透水面扩张对洪峰的影响}

3.2.1 全流域的不透水面扩张对洪峰的影响 为分析近 30 年来不透水面扩张对流域洪峰带来的影响, 利用 1988-2015 年间的 1988、1994、2001、2006、2009、2011、2013 和 2015 年 8 期土地利用构建只有不透水面积随 年份变化,非不透水面保持 1988 年结构相应减少的 8 个不透水面扩张情景, 以此保证流域洪峰的变化仅受 到不透水面扩张影响. 模拟 10 场洪水在上述城市化情景下的洪水过程结果, 得到不同年份情景下 10 场洪 水的平均洪峰流量 (图 4), 同时再根据 10 场洪水在 1988 年土地利用情景下的洪峰流量大小进行分级, 将洪 峰在 $700 \mathrm{~m}^{3} / \mathrm{s}$ 以上的洪水划分为大洪水事件, 洪峰小于 $700 \mathrm{~m}^{3} / \mathrm{s}$ 的洪水划分为小洪水事件, 分析不同量级 洪水在不同年份不透水面情景下的洪峰及其与 1988 年洪峰相比的涨幅,结果见表 5.

在不透水面扩张的情况下, 10 场洪水的洪峰均呈现增长趋势 (表 5), 在 2015 年不透水面情景下的 10

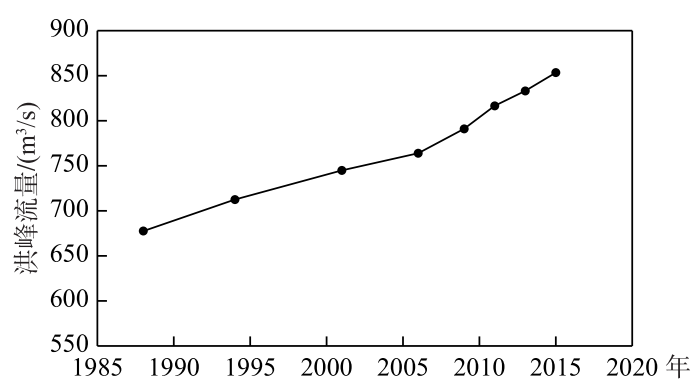

图 4 1988-2015 年 8 个不透水面扩张情景下 10 场洪水平均洪峰流量变化

Fig.4 Changes in average peak discharge of 10 floods under 8 urbanization scenarios from 1988 to 2015
场洪水洪峰相较于 1988 年平均增加了 $27.21 \%$, 说 明不透水面的扩张会使流域洪峰流量显著增加. 全 流域不透水面的扩张对不同量级洪水的影响有明显 的差异, 当不透水面增加相同幅度时, 小洪水对不透 水面扩张响应的敏感度较高, 2015 年不透水面情景 下的洪峰相较于 1988 年平均涨幅达到 $31.96 \%$; 而 大洪水的敏感度则低于小洪水, 平均涨幅为 $22.45 \%$. 同时由图 4 可知, 在 2006 年前后洪峰流量增速有明 显变化, 前期年均增长率为 $0.67 \%$, 后期为 $1.24 \%$, 2006-2015 年的洪峰流量增长速度明显大于19882006 年. 这与全流域不透水面扩张速度的变化趋势 一致, 全流域在 2006-2015 年的不透水面年均增长 率大于 2006 年之前, 可见伴随着整个秦淮河流域的 不透水面扩张, 城市化后期带来的洪峰增长速度大 
于城市化初期.

表 5 不同量级洪水的洪峰涨幅对比

Tab.5 Comparison of flood peak increases of different magnitudes

\begin{tabular}{|c|c|c|c|c|c|c|}
\hline \multirow{2}{*}{ 洪水量级 } & \multirow{2}{*}{ 洪水场次 } & \multirow{2}{*}{$\begin{array}{c}1988 \text { 年洪峰/ } \\
\left(\mathrm{m}^{3} / \mathrm{s}\right)\end{array}$} & \multicolumn{3}{|c|}{ 较 1988 年洪峰涨幅/\% } & \multirow{2}{*}{$\begin{array}{c}2015 \text { 年平均涨幅 } \\
\%\end{array}$} \\
\hline & & & 1994 年 & 2006 年 & 2015 年 & \\
\hline \multirow[t]{5}{*}{ 小洪水 } & 201007 & 515.3 & 8.79 & 22.86 & 45.26 & 31.96 \\
\hline & 201106 & 551.3 & 7.02 & 18.07 & 34.84 & \\
\hline & 201207 & 372.5 & 7.25 & 17.02 & 35.57 & \\
\hline & 201208 & 676.3 & 3.25 & 6.33 & 17.21 & \\
\hline & 201307 & 624.3 & 5.48 & 14.11 & 26.94 & \\
\hline \multirow[t]{5}{*}{ 大洪水 } & 199607 & 726.9 & 4.72 & 11.98 & 23.90 & 22.45 \\
\hline & 200808 & 785.4 & 4.74 & 12.11 & 23.80 & \\
\hline & 200907 & 919.4 & 5.33 & 12.54 & 27.44 & \\
\hline & 201107 & 732.5 & 2.99 & 7.89 & 14.66 & \\
\hline & 201407 & 871.6 & 4.58 & 11.07 & 22.46 & \\
\hline
\end{tabular}

3.2.2 不透水面扩张分布位置对洪峰的影响 进一步分析秦淮河流域不透水面扩张的分布位置对洪水的影 响差异,首先根据流域各支流主要汇水单元, 按照溧水河流域、句容河流域和主干河流域将秦淮河流域划分 为 3 个流域单元 (图 5), 分析不透水面扩张发生在流域上、下游时对洪峰影响的差异. 利用 1988-2015 年间 不透水面空间分布数据, 实现下述 3 种不透水面扩张情景下的洪水洪峰变化情况分析, 即: 不透水面扩张分 别只发生在溧水河流域、句容河流域和下游主干河流域,且在相应单元内只发生不透水面的扩张,其他单元 内不透水面则保持 1988 年的情形不变.

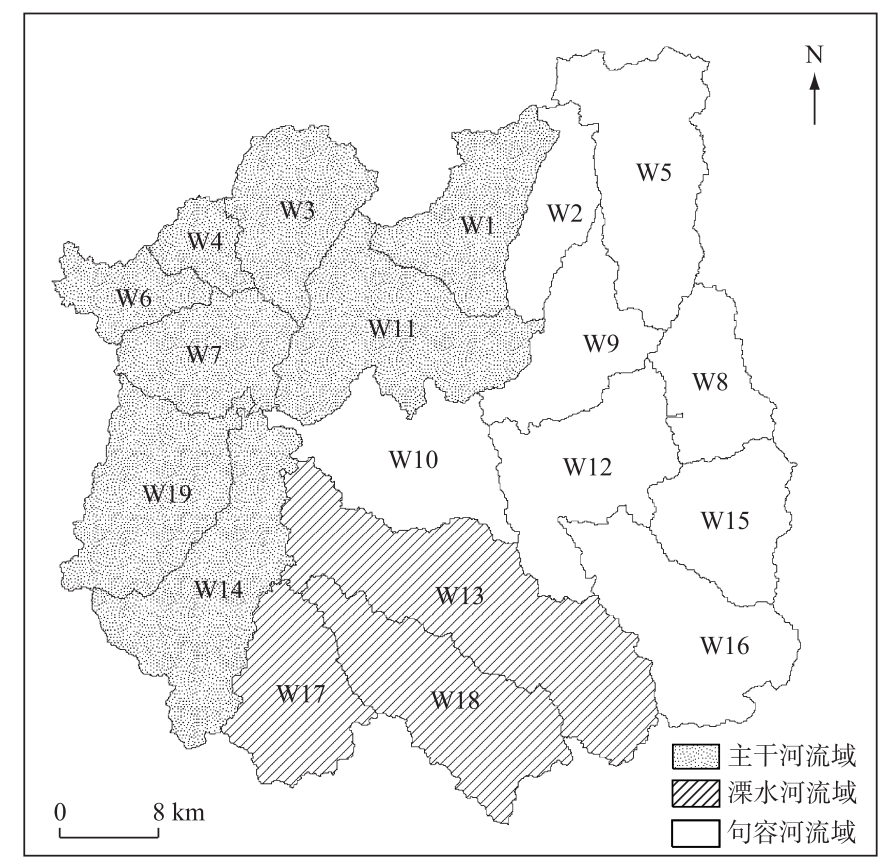

图 5 上下游空间格局划分

Fig.5 Spatial pattern division of upper and lower reaches 
模拟 10 场洪水在上述情景下垫面状况下的洪水过程(表 6), 可以发现: 1988-2015 年间各流域单元的 不透水面扩张均导致洪峰流量的增加. 在控制只有 1 个单元发生不透水面扩张时,近 30 年来下游主干河流 域的城市化带来的洪峰涨幅最为显著, 10 场洪水洪峰的涨幅平均为 $14.98 \%$; 句容河流域次之,城市化带来 的洪峰流量平均增长 $6.34 \%$;溧水河流域最低.

然而各单元不透水面扩张带来的洪峰涨幅与其不透水面增长幅度并不一致 (表 6). 如下游主干河流域 的不透水面增加量约为句容河流域的 3 倍多, 但其对应的洪水的洪峰流量平均涨幅仅为句容河流域的两倍 多,可见各流域单元城市化对洪水要素的影响大小不仅与其不透水面积增长量有关, 可能还受到不透水面 分布位置的影响.

表 6 各流域单元洪峰流量平均涨幅与不透水面积变化对比

Tab.6 Comparison of average increase of flood peak discharge and impervious area in each basin unit

\begin{tabular}{ccccc}
\hline 流域 & 1988 年不透水面积 $/ \mathrm{km}^{2}$ & 2015 年不透水面积 $/ \mathrm{km}^{2}$ & 不透水面增加量 $/ \mathrm{km}^{2}$ & 洪峰流量平均涨幅 $/ \%$ \\
\hline 主干河流域 & 43.79 & 321.98 & 278.19 & 14.98 \\
溧水河流域 & 16.61 & 96.67 & 80.06 & 5.06 \\
句容河流域 & 40.59 & 129.75 & 89.16 & 6.34 \\
\hline
\end{tabular}

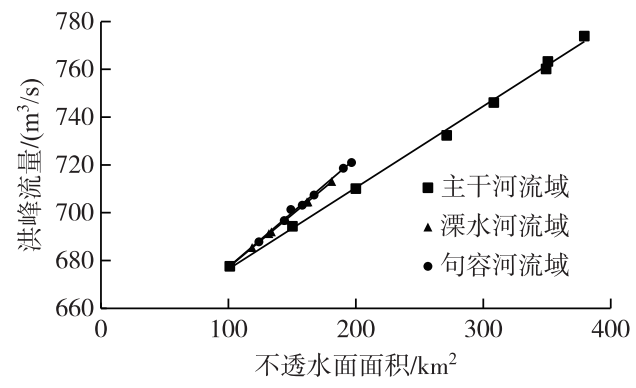

图 6 流域空间格局情景下不透水面 面积和洪峰流量变化

Fig. 6 Changes in impervious surface area and flood peak discharge under the spatial pattern of the basin

在 1988-2015 年研究时段内,秦淮河流域两河源地 区和下游主干河流域的洪峰流量与不透水面积均呈线性 增长关系 (图 6). 溧水河流域、句容河流域的单位不透水 面扩张的洪峰涨幅十分接近, 且均显著大于下游主干河 流域, 即两河源流域的单位面积不透水面扩张的洪峰效 应更为显著, 为流域洪峰的主要贡献区, 大于流域出口处 的单位面积不透水面扩张带来的洪峰效应.

洪峰在空间上对不透水面变化的响应差异与产汇流 特性有关,上游地区的不透水面积增加导致地表径流增 大,汇流至出口处加大了洪峰流量,而下游主干河流域增 加的地表径流很快汇人出口断面, 致使洪峰流量响应减 弱. 这与 Marsh 等、Shuster 等和李倩的研究结论一 致 ${ }^{[21-22,31]}$, 更靠近流域源头的城市开发对洪水的影响尤 为明显,大于流域下游地区城市化的洪水效应. 同时因为 秦淮河流域内溧水河源和句容河源流域主要地形为丘陵山区, 下游主干河流域主要位于平原地区, 可能由 于山区特殊的地形地貌特点, 洪水来临时往往流速较大 ${ }^{[32]}$. 曾杉通过实验发现随着沟道坡度的增加, 各重 现期下洪峰流量有明显增大的趋势 ${ }^{[33]}$, 秦淮河流域的地形特征可能加剧了洪峰对上下游不透水面变化的响 应差异.

因此对秦淮河流域来说, 其上游溧水河和句容河两河源流域的单位面积不透水面扩张对洪峰影响大于 下游主干河流域, 而两河源流域还处于城市化和不透水面扩张的早期, 自 2006 年以来不透水面扩张速度较 快, 扩张潜力较大, 未来洪峰增长潜力较大, 给秦淮河流域带来一定的防洪压力, 因此在城市化过程中应更 加注意结合其发展制定防洪减灾与可持续发展对策.

\section{3 不同量级洪水对流域不透水面空间扩张的响应差异}

由 3.2.1 节分析可知 1988-2015 年全流域的不透水面扩张对不同量级洪水的影响有差异, 小洪水在 2015 年不透水面情景下的洪峰相较于 1988 年平均涨幅大于大洪水. 为分析不同量级洪水对秦淮河流域不 同位置上的不透水面扩张的敏感度差异, 分别计算了当不透水面扩张只发生在溧水河流域、句容河流域和 主干河流域时大、小洪水与 1988 年相比的洪峰涨幅随不透水面积的变化情况 (图 7).

当不透水面扩张发生在溧水河流域、句容河流域和主干河流域不同位置时, 研究时段内大、小洪水的洪 峰涨幅与不透水面积均呈线性正相关关系, 且下游主干河流域的大、小洪水洪峰涨幅差距略大于溧水河流 

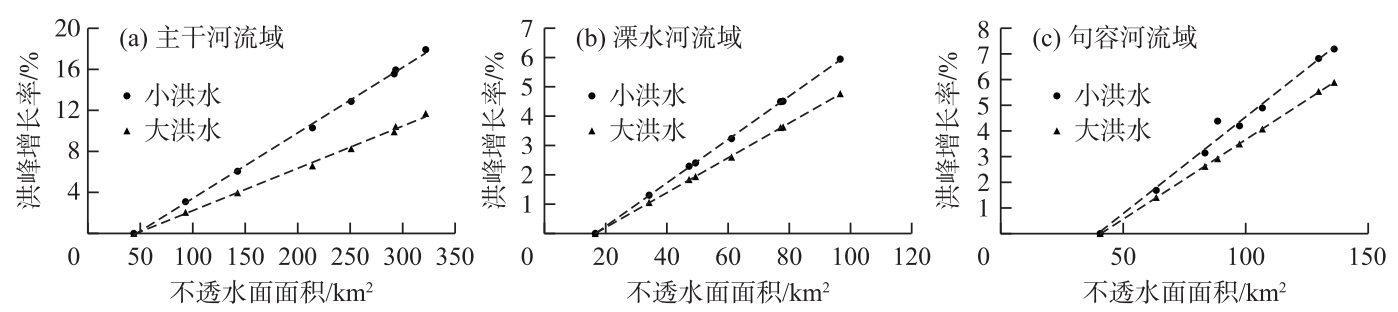

图 7 流域空间格局情景下不同量级洪水洪峰流量变化

Fig.7 Changes in flood peak discharge of different magnitudes under the spatial pattern of the basin

域、句容河流域. 对于秦淮河全流域及不同位置的不透水面扩张情景,均发现小洪水的洪峰涨幅大于大洪水 的涨幅,这主要是由于洪水过程是受气象因素和下垫面共同作用的结果 ${ }^{[34]}$, 而大洪水是气象因素占主导, 从 而弱化了下垫面不透水面积的作用,因此当不透水面增加相同幅度时, 大洪水对土地利用变化响应的敏感 度低于小洪水. Du 等和 Kaspersen 等 ${ }^{[15,35]}$ 的研究也都得出城市化对小洪水影响更大的结论, 并认为其原因 主要是规模较大的洪水一般有强度大与持续时间长的降雨条件, 降雨强度远超出土壤的下渗能力, 使降雨 事件后期土壤的性质类似于不透水面, 从而弱化了不透水面积大小对大洪水的影响.

\section{4 结论}

1) 随着城市化的快速发展, 秦淮河全流域不透水面显著扩张, 其中溧水区和句容市近年来不透水面扩 张速度明显加快, 超过了南京城区和江宁区; 全流域的不透水面扩张情景下洪水洪峰流量呈现逐年增加的 趋势, 2015 年城市化情景下的 10 场平均洪峰流量相比于 1988 年增长 $27.21 \%$, 伴随着不透水面扩张, 洪涝威 胁日益加剧.

2) 在全流域不透水面扩张的影响下, 研究时段内在 2006 年前后的洪峰年均增长率有明显变化,整个秦 淮河流域在 2006-2015 年的不透水面扩张带来的洪峰增长率大于城市化相对较早时间.

3) 流域不同位置的单位面积不透水面扩张带来的洪峰涨幅不同. 由于上下游位置和下垫面地形的共同 影响, 秦淮河流域上游溧水河和句容河两河源流域的单位面积不透水面扩张对洪峰的影响大于下游主干河 流域, 且在研究时段内洪峰流量随着不透水面增加呈线性增长, 未来不透水面扩张给秦淮河流域带来的防 洪压力较大.

4) 不同量级洪水对秦淮河流域各不透水面扩张情景下的洪峰响应有所差异: 在全流域及不同位置的不 透水面扩张情景下,小洪水的敏感程度均大于大洪水,且下游主干河流域不透水面扩张情景下的大、小洪水 洪峰涨幅差距略大于溧水河、句容河两河源流域.

\section{5 参考文献}

[ 1 ] Zhang JY, Song XM, Wang GQ et al. Development and challenges of urban hydrology in changing environment- I . Urban hydrological effect. Progress of Water Science, 2014, 25(4): 594-605. [ 张建云, 宋晓猛, 王国庆等. 变化环境下城 市水文学的发展与挑战—I I. 城市水文效应. 水科学进展, 2014, 25(4) : 594-605.]

[ 2 ] Xu YP, Ding JJ, Chen Y. Hydrological effects of urbanization in the Yangtze River Delta. Journal of Water Conservancy and Transportation Engineering, 2009, (4): 67-73. [许有鹏, 丁瑾佳, 陈芗. 长江三角洲地区城市化的水文效应研 究. 水利水运工程学报, 2009, (4): 67-73.]

[ 3 ] Winter JM, Huang H, Osterberg EC et al. Anthropogenic impacts on the exceptional precipitation of 2018 in the mid-Atlantic United States. Bulletin of the American Meteorological Society, 2019, 101(1) : 5-10. DOI: 10.1175/BAMS-D-190172.1 .

[ 4 ] Xu JT, Xu YP, Ye ZW. Experimental observation and simulation of hydrological process in urbanization area: a case study of Anji experimental plot in Xitiaoxi basin of Taihu Lake. Resources and environment of Yangtze River Basin, 2011, 20(4) : 445-450. [ 徐金涛, 许有鹏, 叶正伟. 城镇化地区水文过程实验观测与模拟一一太湖西苕溪流域安吉实验小区为 
例. 长江流域资源与环境, 2011, 20(4): 445-450.]

[ 5 ] Wang Q, Xu YP, Wang YF et al. Comparative experimental observations and hydrological response in representative basins of eastern China. Advances in Water Science, 2019, 30(4) : 467-476. [王强, 许有鹏, 王跃峰等. 中国东部不同特征小 流域水文对比观测试验分析. 水科学进展, 2019, 30(4): 467-476. $]$

[ 6 ] Zhou ZZ, Smith JA, Yang L et al. The complexities of urban flood response: Flood frequency analyses for the Charlotte metropolitan region. Water Resources Research, 2017, 53(8) : 7401-7425. DOI: 10.1002/2016WR019997.

[ 7 ] Zhang W, Villarini G, Vecchi GA et al. Urbanization exacerbated the rainfall and flooding caused by hurricane Harvey in Houston. Nature, 2018, 563(7731) : 384-388. DOI : 10.1038/s41586-018-0676-z.

[ 8 ] Rajib A, Merwade V. Hydrologic response to future land use change in the upper Mississippi River Basin by the end of 21st century. Hydrological Processes, 2017, 31(21) : 3645-3661. DOI: 10.1002/hyp.11282.

[ 9 ] Prosdocimi I, Kjeldsen TR, Miller JD. Detection and attribution of urbanization effect on flood extremes using nonstationary flood-frequency models. Water Resources Research, 2015, 51(6) : 4244-4262. DOI: 10.1002/2015WR017065.

[10] Wissmar RC, Timm RK, Logsdon MG. Effects of changing forest and impervious land covers on discharge characteristics of watersheds. Environmental Management, 2004, 34(1) : 91-98. DOI: 10.1007/s00267-004-0224-5.

[11] Wan RR, Yang GS, Li HP. Flood response to land-use and land-cover change: A case study of Xitiao Rivulet Basin in upper reach of Taihu Lake. Journal of Natural Disasters, 2008, 17(3): 10-15. [万荣荣, 杨桂山. 流域土地利用/覆被变 化的洪水响应一一太湖上游西芳溪流域为例. 自然灾害学报, 2008, 17(3): 10-15.]

[12] Ge Y, Shi PJ, Zhou JH et al. Simulation of flood disaster scenario under driving action of land use change in urb of Shanghai. Journal of Natural Disasters, 2003, 12(3) : 25-30. [葛怡, 史培军, 周俊华等. 土地利用变化驱动下的上海市区 水灾灾情模拟. 自然灾害学报, 2003, 12(3): 25-30.]

[13] Zheng J, Fang WH, Shi PJ et al. Modeling the impacts of land use change on hydrological processes in fast urbanizing region-A case study of the Buji watershed in Shenzhen City, China. Journal of Natural Resources, 2009, 24(9) : 15601572. [郑璟, 方伟华, 史培军等. 快速城市化地区土地利用变化对流域水文过程影响的模拟研究一一以深圳市布 吉河流域为例. 自然资源学报, 2009, 24(9): 1560-1572.]

[14] Chen X, Tian C, Meng X et al. Analyzing the effect of urbanization on flood characteristics at catchment levels. Proceedings of the International Association of Hydrological Sciences, 2015, 370: 33-38. DOI: 10.5194/piahs-370-33-2015.

[15] Du JK, Qian L, Rui HY et al. Assessing the effects of urbanization on annual runoff and flood events using an integrated hydrological modeling system for Qinhuai River basin, China. Journal of Hydrology, 2012, 464/465 : 127-139. DOI: 10. 1016/j.jhydrol.2012.06.057.

[16] Choi W, Deal BM. Assessing hydrological impact of potential land use change through hydrological and land use change modeling for theKishwaukee River basin (USA). Journal of Environmental Management, 2008, 88(4) : 1119-1130. DOI: 10.1016/j.jenvman.2007.06.001

[17] Bhaduri B, Minner M, Tatalovich S et al. Long-term hydrologic impact of urbanization: A tale of two models. Journal of Water Resources Planning \& Management, 2001, 127 (1) : 13-19. DOI: 10.1061/( ASCE) 0733-9496 (2001) 127: 1 (13).

[18] Rui XF, Liu FG, Xing ZX. Advances in hydrology and some frontier problems. Advances in Science and Technology of Water Resources, 2007, 27 (1) : 75-79. [芮孝芳, 刘方贵, 邢贞相. 水文学的发展及其所面临的若干前沿科学问题. 水 利水电科技进展, 2007, 27 (1): 75-79.]

[19] Wang Q, Xu YP, Gao B et al. Runoff spatial responses to land use change in Xitiaoxi River Basin. Journal of Natural Resources, 2017, 32(4) : 632-641. DOI: 10.11849/zrzyxb.20160455. [王强, 许有鹏, 高斌等. 西苕溪流域径流对土地 利用变化的空间响应分析. 自然资源学报, 2017, 32(4) : 632-641.]

[20] Zheng PQ, Baetz BW. GIS-based analysis of development options from a hydrology perspective. Journal of Urban Planning and Development, 1999, 125(4) : 164-180. DOI: 10.1061/(asce)0733-9488(1999) 125: 4(164).

[21] Marsh WM, Marsh NL. Hydrogeomorphic considerations in development planning and stormwater management, central Texas Hill Country, USA. Environmental Management, 1995, 19(5) : 693-702. DOI: 10.1007/BF02471952.

[22] Shuster WD, Bonta J, Thurston H et al. Impacts of impervious surface on watershed hydrology: A review. Urban Water Journal, 2005, 2(4) : 263-275. DOI: 10.1080/15730620500386529.

[23] Yi JJ. Study on flood forecasting and dispatching model of Qinhuai River Basin [Dissertation]. Nanjing: Hohai University, 
2005. [易建军. 秦淮河流域洪水预报与调度模型研究 [ 学位论文]. 南京: 河海大学, 2005.]

[24] Shi Y, Xu YP, Cai J. Analysis of the impact of urbanization on flood risk in the middle and lower reaches of Qinhuai River. Research of Soil and Water Conservation, 2011, 18(5) : 26-31. [石怡, 许有鹏, 蔡娟. 城市化对秦淮河中下游洪港 灾害风险的影响分析. 水土保持研究, 2011, 18(5): 26-31.]

[25] Mao L, Zhang HM. Empirical analysis of rainstorm waterlogging influencing factor in Nanjing based on urbanized factor. Economic Research Guide, 2011, (3) : 136-138. [毛否, 张慧明. 基于城市化因子的南京市内涝影响因素实证分析. 经济研究导刊, 2011, (3): 136-138.]

[26] Yang HW, Chen X, Gao B. Influence of urbanization process on urban waterlogging risk change in Qinhuai River Basin. Jiangsu Water Resources, 2020, (10) : 50-57. [杨红卫, 陈璇, 高斌. 秦淮河流域城市化进程对城市内涝风险变化 的影响. 江苏水利, 2020, (10): 50-57.]

[27] Xu HQ, Wang MY. Remote sensing-based retrieval of ground impervious surfaces. Journal of Remote Sensing, 2016,20 (5) : 1270-1289. DOI: 10.11834/jrs.20166210. [徐涵秋, 王美雅. 地表不透水面信息遥感的主要方法分析. 遥感学 报, 2016, 20(5): 1270-1289.]

[28] Gao YQ, Yuan Y, Wang HZ et al. Examining the effects of urban agglomeration polders on flood events in Qinhuai River basin, China with HEC-HMS model. Water Science and Technology, 2017, 75(9/10) : 2130-2138. DOI: 10.2166/wst. 2017.023.

[29] Zhao YC, Wang JH, Liang JP et al. Application of HEC-HMS for hydrological simulation in Zijingguan watershed. Water Resources and Power, 2017, 35(12)：10-13. [赵永超, 王加虎, 梁菊平等. HEC-HMS 模型在紫荆关流域水文模拟 中的应用. 水电能源科学, $2017, \mathbf{3 5}$ (12): 10-13.]

[30] Lei CG, Xu YP, Zhang QY et al. Impacts of land-use change on flood process and frequency of various return periods: A case study of Jiaokou Reservoir watershed in Fenghua River. Acta Ecologica Sinica, 2016, 36( 16) : 5017-5026. DOI: 10. 5846/stxb201501220183. [雷超桂, 许有鹏, 张倩玉等. 流域土地利用变化对不同重现期洪水的影响一一奉化江 晈口水库流域为例. 生态学报, 2016, 36(16): 5017-5026.]

[31] Li Q. Urbanization spatial pattern changes and hydrological effects in the Qinhuai River Basin [Dissertation]. Nanjing: Nanjing University, 2012. [李倩. 秦淮河流域城市化空间格局变化及其水文效应 [学位论文]. 南京: 南京大 学, 2012.]

[32] Yuan J. Research on the impact of urbanization on flood characteristics of small and medium rivers in mountainous areas [Dissertation]. Chongqing: Chongqing Jiaotong University, 2018. [袁江. 城市化对山区中小河流洪水特性影响研究 [学位论文]. 重庆: 重庆交通大学, 2018.]

[33] Zeng S. Generalized experimental study of flood response to different basin topography under the same rainfall process [Dissertation]. Xi'an University of Technology, 2018. [曾杉. 相同降雨过程下洪水对不同流域地形响应的概化试验研究 [学位论文]. 西安: 西安理工大学, 2018.]

[34] Xu YP, Yu RH, Ma ZW. Analysis on the cause of formation of flood disaster and flood characteristics in the middle and lower reaches of the Yangtze River. Resources and Environment in the Yangtze Basin, 2005, 14(5): 638-643. [许有鹏, 于瑞宏，马宗伟. 长江中下游洪水灾害成因及洪水特征模拟分析. 长江流域资源与环境, 2005, 14(5): 638-643.]

[35] Skougaard Kaspersen P, Høegh Ravn N, Arnbjerg-Nielsen K et al. Influence of urban land cover changes and climate change for the exposure of European cities to flooding during high-intensity precipitation. Proceedings of the International Association of Hydrological Sciences, 2015, 370: 21-27. DOI: 10.5194/piahs-370-21-2015. 